\title{
أسس نظرية في مقومات العملية التعليمية
}

\section{د.حميدة على الماطولي}

كلية الآداب - جامعة مصراتة

\section{مقدمة:}

الحمد لله رب العالمين والصلاة والسلام على معلمنا وقدوتنا الهادي المبعوث ليتمم

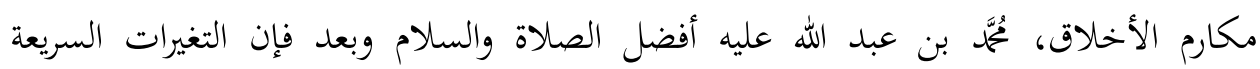
والمتلاحقة أسهمت في خلق التباين والاختلاف في أنماط الحياة الاجتماعية والثقافية، ويتطلب من مؤسسات البجتمع وتنظيماته تلبية الوظائف المتغيرة والمتجددة بما يقلل من التباين والاختلاف، ويلبي احتياجات المجتمع المتطورة، والمدرسة مركز إشعاع يؤدي وظائف عديدة بصورة رسمية أو غير رسمية، ينبغي عليها استيعاب التطورات والمستجدات التعليمية والتربوية في

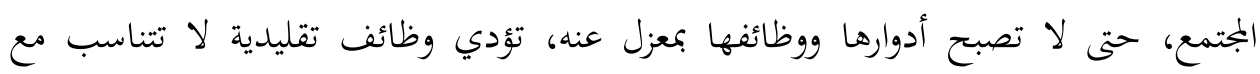
المتطلبات التربوية الحديثة، ولا تتواءم مع سوق العمل وخطط التنمية واحتياجات المجتمع. إنَّ المدرسة وسط تربوي تتطلب توافر مقومات أساسية تستند عليها في أداء وظائفها وإشباع حاجات أفردها، ويمكن تصنيف المقومات وفق متطلبات العملية التعليمية والتربوية كالمقومات البشرية والمادية وشبه المادية. و تأتي هذه الورقة البحثية لتلقي الضوء على خمسة محاور

$$
\begin{aligned}
& \text { أولاًا: موضوع البحث وأهميته. } \\
& \text { ثانيًا: مفاهيم تربوية مستخدمة في البحث. } \\
& \text { ثالثا: الهدف العام للبحث. } \\
& \text { رابعًا: مقومات العملية التعليمية. } \\
& \text { 4-1. المقومات البشرية للمدرسة. }
\end{aligned}
$$




\section{2-4 2-4. المقومات المادية للمدرسة. \\ 3-4 \\ خامسًا: ملخص البحث والتوصيات والمقترحات. \\ أولا: موضوع البحث وأهميته}

يواجه التعلم في ليبيا تحديات وعقبات وموروثًا تنظيميًّا (أساليب التفكير والقيم والاعتقادات والسلوكيات) يعد امتدادًا للثقافة المجتمعية السائدة التي تعيق جودة التعليم في ليبيا، والتي يمكن تدارك بعضها ومواجهتها من خلال العمل على بناء مؤسسات تربوية تعليمية تتوافر

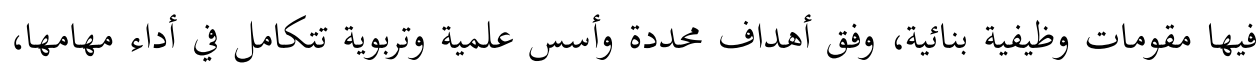
ووظائفها بشكلها المناسب والائق مع التطور الذي تمر به المجتمعات، وبما يكفل نموَّا تربويًّا متكاملاً لبناء الإنسان وفق أسس تربوية واجتماعية وعقائدية سليمة نابعة من عقيدتنا الإسلامية. والمتأمل في واقع التعليم في ليبيا بالمؤسسات الموجودة حاليًّا يجد بوضوح -بكل أسف-

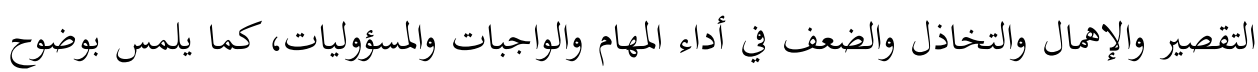
الأخطاء والمغالطات التربوية والتعليمية والفكرية التي هي غنية عن الإبراز أو التطرق لها، فكل

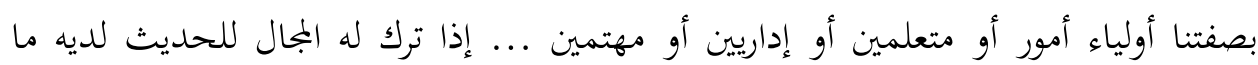
يقول عن الأخطاء التي ترتكب في قضايا التعليم وهيكلته وبنائه وفلسفته ومقوماته ومخرجاته ومؤسساته، وعلى سبيل المثال لا الحصر وجود المعلمين في غير تخصصاتم ووجود الطلبة العاديين -الأسوياء- مع الطلبة غير العاديين الذين يحتاجون للرعاية والتربية الخاصة بمبرات

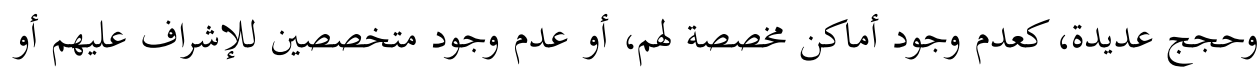
عدم اعتراف أسرهم بالمشكلة.

وعند النظر في هذا الأساس الضعيف في بناء التعليم ووظائفه والنظر في طبيعة مشكلاته وأسباهما المتعددة الشائكة يلمس الباحث بوضوح حجم الخسائر، سواء أكانت مادية أو بشرية، وحجم الإهدار والفاقد التعليمي من رسوب وتسرب وتأخر وتخلف وضعف تحصيلي، 
فالهروب من المدرسة والغياب غير المبرر أصبح من سمات مدارسنا، مع أن الغياب والمروب ليس الفيس

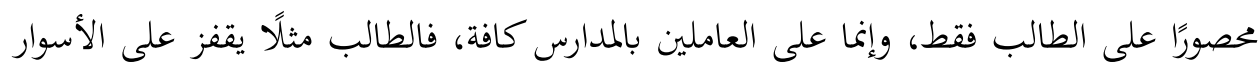
العالية المخيطة بالمدرسة، والمعلم يخرج من بابها بسهولة ويسر.

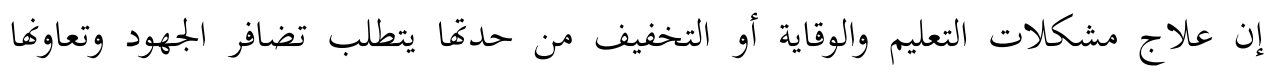

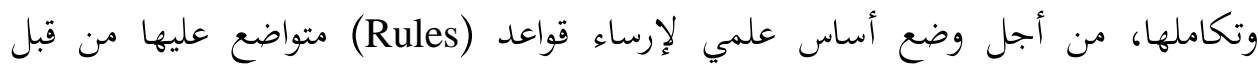

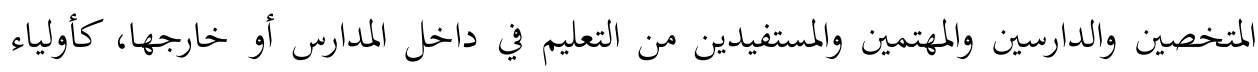

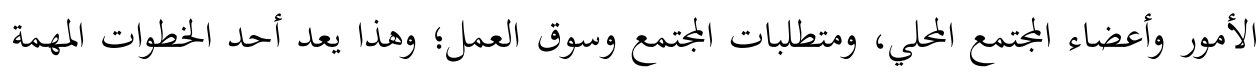

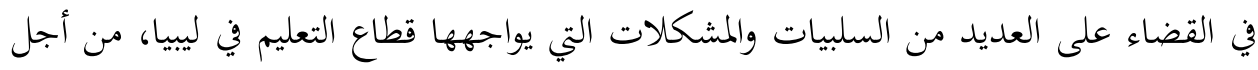

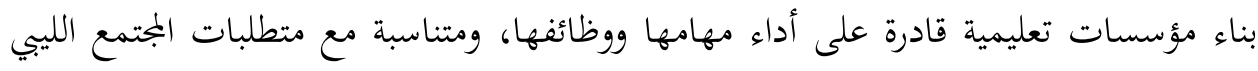

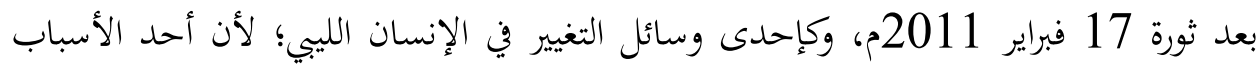

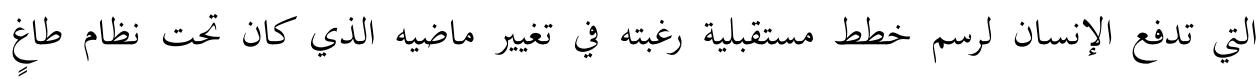

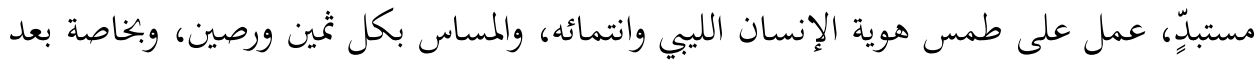

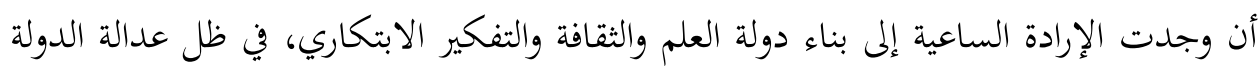

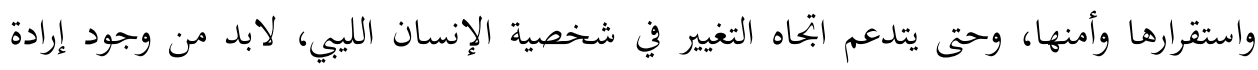

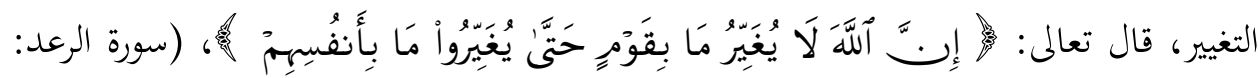

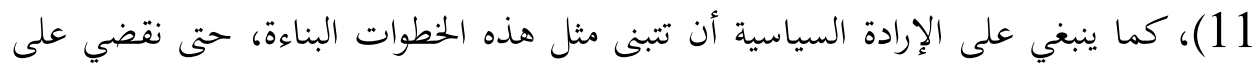
إغراق التعليم في لفظية رسم خطط نظرية وكثرة الكلام والأحلام؛ لأن الاجتهادات والأبحاث والدراسات العلمية تعد أهم الخطوات الناجحة في مواجهة التحديات والصعوبات والمشكلات.

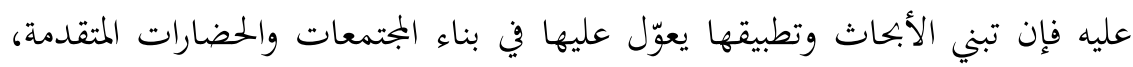

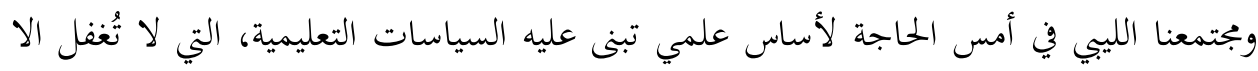

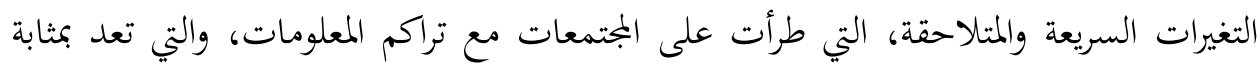
تحديات تتطلب إعادة النظر في مقومات التعليم في ليبا، ومن أهم التحولات والتغيرات ما يأتي: 
1 الثورة التكنولوجية Technology Revolution.

2. الثورة العليمة والمعرفية Science \& Knowledge Revolution.

3. التحولات الإدارية Transformations of Management.

4. التحولات التربوية Transformations of Education.

5. الجودة الشاملة في التعليم Total Quality Management in Education.

$$
\text { 1 وفيما يلي نوضح بعض أهم التحولات والتغيرات بشيء من التبسيط: }
$$

إن التغيرات السريعة والمتلاحقة في التقنيات فرضت نفسها كفن استخدمه الإنسان من

أجل دعم وظائف التربية، وتسهيل أداء العديد من الوظائف في عملية التعليم والتعلم، فقد برزت التهن

أهمية (تكنولوجيا التعليم) كتنظيم متكامل يضم عناصر أساسية في العملية التربوية وهي:

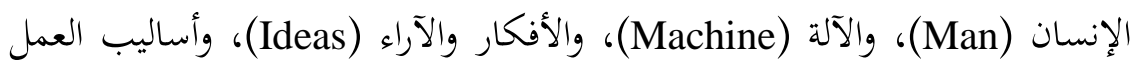

(Procedures)، والإدارة (Management)، ومن خلال تكنولوجيا التعليم يتم الاستخدام الأمثل للمصادر التعليمية بتطبيق شروط التعليم المستمدة من الحقائق ونظريات التعليم الإنساني بأسلوب التنظيم؛ لضمان استخدام المصادر التعليمية في مقومات تعليمية تحقق أهدافًا تعليمية التعبية مسبقة التحديد، والتوصل إلى تعلم أكثر فعالية، ومفهوم تطور تكنولوجيا التعليم تطور بمراحل

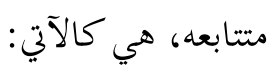

المرحلة الأولى: التعليم المرئي والمسموع عن طريق جميع الحواس. المرحلة الثانية: الوسائل التعليمية كمعينات للتدريس.

المرحلة الثالثة: الوسائل التعليمية وسيط بين المعلم والمتعلم (عملية الاتصال). المرحلة الرابعة: الوسيلة جزء من منظومة التعليم.

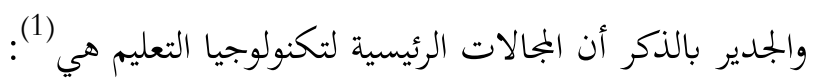

1- عبداللطيف بن الصفي الجزار، مقدمة في تكنولوجيا التعليم النظرية والعملية، القاهرة، كلية البنات، جامعة عين شمس، 1994م. 


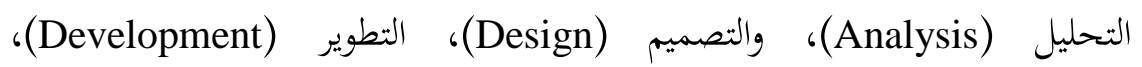

والاستخدام (Utilization)، والإدارة (Management)، التي تؤدي وظائف غاية في الأهمية بالإضافة إلى التقيم (Evaluation)، من أجل الحكم على كفاءة عمليتي التعليم والتعلم. ويعد التصميم التعليمي أحد المجالات الهامة لتكنولوجيا التعليم، وعند النظر في مفهوم

تصميم التعليم (Instructional Design) يمكن القول بأن رسم خريطة ذهنية متكاملة ترشد الفرد إلى خطوات التنفيذ والاستمرار في تحقيق الأهداف أي عملية هندسية لموقف "ما" دلالات على التصميم، في حين أن التصميم التعليمي كعلم يبحث في وصف أفضل الطرق التعليمية التي تحقق النتاجات التعليمية المرغوب فيها وتطويرها وفق شروط معينة، كما يمكن تعريفها بأها تقنية لتطوير التعليم وخبراته وبيئاته، والتي من شأفا تحسين الأنشطة التعليمية وجعلها أكثر فعالية، وتوجد بعض التجارب والخبرات والنماذج التي قدمت كنماذج لتصميم التعليم، كنموذج كمب

(Kemp)

\section{2. - 2 الثورة العلمية والمعرفية:}

إن تزايد سرعة تراكم المعلومات والخبرات والنمو المعرفي الذي أفرز التنوع والتعقد

وبخاصة بعد أن فتحت العولمة (Globalization) المجال العالمي الواسع في التواصل مع حضارات أخرى، والتواصل بين الشرق والغرب مع إزالة الحواجز بين المجتمعات، دون قيود أو حدود بما أسهم في التنوع الثقافي والفكري ... ينبغي وضعه بحذر في الاعتبار في فلسفة التربية وقضاياها بما يكفل ترسيخ الهوية الإسلامية (Belongingness).

1- للمزيد ينظر: مُحَّمَ محمود الحيلة، التصميم التعليمي نظرة وممارسة، عمان، دار الميسرة للنشر والتوزيع

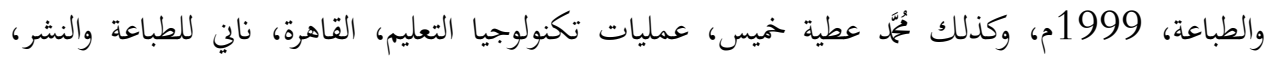
2003 


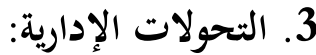

تعد الإدارة أساسا للنجاح والتقدم والرقي بالمجتمع، وإن كانت الإدارة الناجحة والفعالة هي ركيزة جهود إنسانية منظمة تعمل على استثمار وتوظيف الموارد البشرية والمادية المتاحة، من أجل تحقيق الأهداف المحددة.

وتؤدي الإدارة العديد من المهام والوظائف، والإدارة المدرسية جزء من الإدارة التربوية،

فهي متداخلة متفاعلة مع أنواع الإدارات الأخرى وتؤدي وظائفها العامة التي من أهمها: التخطيط والتنظيم والتوجيه والقيادة والرقابة والمحاسبة والتجديد والتقييم والمتابعة والاتصال ....

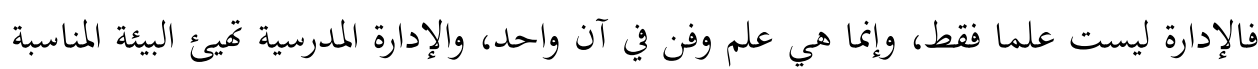

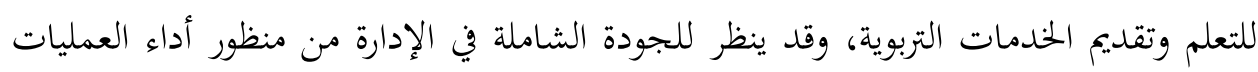
الإدارية دون أخطاء، أو تقصير بما يشبع رغبات واحتياجات المستفيدين والمجتمع عامة.

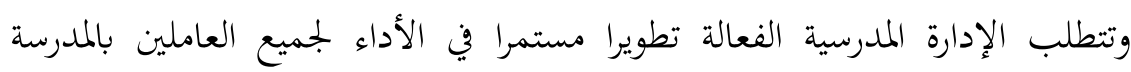
لضمان الحصول على أفضل المخرجات (Output Quality) والقيادة الإدارية بالمدرسة، هي لهي المحرك الأساسي للإدارة، وحتى يتحقق مفهوم إدارة الجودة الشاملة على مستوى الإدارة المدرسية يتوجب على القيادات التربوية العمل على مراعاة عدة اعتبارات تضمن حسن الأداء، أهمها: - المشاركة البناءة الفعالة داخل المدرسية. - التحسين والتنمية في العمليات والأداء والإنتاج.

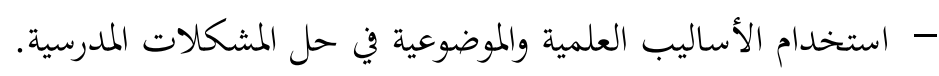
- تحديد معايير واضحة ودقيقة في قياس الأهداف المنشودة. -

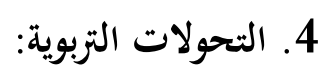

توجد العديد من الأطر المعرفية والفكرية والنظرية والأبحاث والدراسات العلمية التربوية المعاصرة، التي تعد خبرات وبحارب محلية ودولية، أثرت في المجال التربوي التعليمي، وأسهمت في اتساع بجالات التربية ووظائفها وطرقها وأساليبها وابتاهاتا، وأوجدت تحديات أمام المدرسة، 
فنجحت أزمة المدرسة عند الغرب على اجتياز أزمة الفاعلية والكفاءة ومواجهة التحول من الحداثة إلى ما بعد الحداثة، ومن حضارة الصناعة إلى حضارة المعلومات والمعارف، في حين أن أزمة المدرسة العربية - كما هو واضح في مجتمعنا اللبي- ما زالت تبحث عن حلول لمشكلاتما التعليمية والإدارية، كضعف المخرجات التعليمية أو المركزية الإدارية، أو ضعف أداء المعلمين والكفاءة المهنية، أو قلة المباني المدرسية وازدحام الفصول، وعلى سبيل المثال عندما تعرضت المدارس الحكومية في أمريكا وبريطانيا للانتقادات إبان المسابقات الدولية لنيل الامتياز التعليمي (Excellence in Educational) سنة 1994م لدى التلاميذ الأمريكيين، مقارنة بالتلاميذ الآسيويين(1)، وتعالت دعوات للمطالبة بمجتمعات بلا مدارس لأسباب تدني مستوى تحصيل الطلاب وتدني كفايات المعلمين وعدم قدرتم على تحقيق أهداف العملية التعليمية؛ ولذا برزت دراسات بحثية تربوية، بحثت عن أسباب المشكلات، ومن نتائج تلك الدراسات ثلاثه ابتحات بحثية، وهي:

$$
\text { أولًا: حركة بحوث المدارس الفعالة. }
$$

$$
\text { ثانيًا: حركة بحوث تحسين وتطوير المدارس. }
$$

ثالثًا: حركة دمج بكوث المدارس الفعالة مع بحوث تحسين المدرسة. أولًا: حركة المدارس الفعالة: وقد ركزت في البداية على متغيرات هامة كالقيادات التربوية والتحصيل العلمي العالي، واتفاق المهارات الأساسية، والمعلم الكفء، والتقويم المستمر، ثم بدأت المعايير للأداء أكثر تفصيلًا واهتمامًا بدراسة البيئة المحيطة بالتعلم والتدريس.

1- Roger slee, and Gaby weiner (ed.), "introduction: school effectiveness for whom?" in: "school effectiveness for whom", London, Falmer Press, 1998, pp33-47.

Bullock. A. and Thomos. H., "school of the center", London and New York Routledge, 1996, pp. 17-19. 
ثانيًا: حركة بحوث تطوير وتحسين المدارس: أولت اهتمامًا كبيرً بالتغيير التربوي، أو التجديد التربوي ”Management of Educational Change" ومفهوم تحسين تطوير جودة التعليم في إطار ما يسمى بإدارة التغيير يستند على خمسة مبادئ في رأي هويكنز (1):

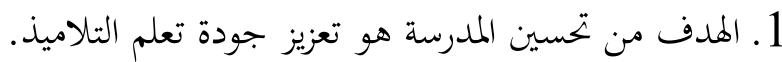

2. التكامل والتساند في تحقيق أهداف المدرسة؛ لأها عملية قم جميع الأطراف. 3. توظيف المدرسة لإمكانياتا وأولوياتا الداخلية في تغيير الضغوط الخارجية.

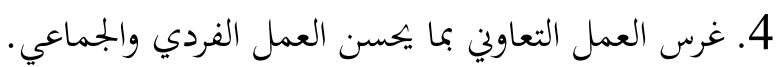

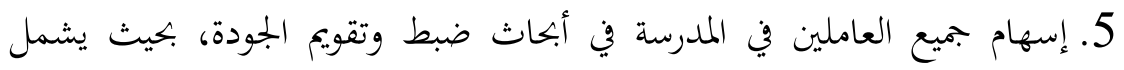

$$
\text { التغيير مستوى المدرسة والمعلم وبجموعات العمل. }
$$

ثالثًا: التجاه بحوث دمج المدارس الفعالة مع بكوث تحسين المدارس: التكامل يقلل من لانتقادات، كإهمال حركة المدارس الفعالة للجانب المهني للمعلم، وركزت على الجوانب التنظيمية للمدرسة، ويمنح هذا الاتحاه الصفة الكمية والنوعية لاتحاه تحسين المدرسة ونقلها من الجانب الاستاتيكي (الثابت) إلى التوجه الديناميكي (المتحرك) في إطار تنمية مهنية مستمرة للمعلمين وتوطينهم بالمدارس وإقرار منطق المنافسة. (Continue Professional Development) 5. أهمية الجودة الشاملة للتعليم (T.Q.M)

اتسعت الجوانب والأبعاد واختلفت التصورات في تحديد معنى الجودة (Quality)، ففي اللغة العربية (ابن منظور) الجودة أصلها: (جود) من الجيد من القول والفعل. أما في القاموس الإنجليزي ويبستر (Webster New World) فتعني: صفة أو درجة تفوّق يمتلكها شيء "ما"، أو درجة الامتياز. ولقد لاقت الجودة في قطاع الصناعة والخدمات نجاحا وتقدما ملموسا، من خلال التركيز على مدى توافق المنتجات مع احتياجات وتطلعات المستفيدين حاليَّا ومستقبلًا.

1- Hopkins, D., et. Al, "Improving the quality of Education for All", London, David Fulton Publishers, 1996, pp. 1-5.

(*) Totall Quality Management in Education. 
فالتركيز على الكيف وليس على الكم، وليس بالضرورة أن تنتج أكثر وإنما من

الضروري جودة المنتجات (1).

وأمام التحديات والأزمات والمشكلات التي يواجهها التعليم طبقت توظيف الجودة

والاستفادة منها بمدلولات ومؤشرات مغايرة لقطاع الصناعة والخدمات، فعملت على الاستفادة من إدارة الجودة في فلسفتها ومخرجاها، فأصبح التركيز على الأداء المدرسي والمناخ المدرسي المناسب لجعل التعليم مصدر سرور ورضا، من هنا برزت مصطلحات هامة ذات دلالات كالمعايير (Excellence) والتميز (Accountability) والمساءلة (Actards) وتقييم الأداء وضمان الجودة (Performance Evaluation) (Feedback)، كما برزت أيضًا مصطلحات تخطيط الجودة، وضبط الجودة، وضمان الجودة، والتحسين في الجودة.

وبهذا ينبغي التركيز على تطوير العمل وتحسينه والإصلاح والتجديد والتغيير المستمر في نوعية التعليم، وإضافة مهام عديدة تساعد المدارس على أن تكون متقدمة ومعاصرة، فالجودة إذن اهتمام عالمي شامل من أجل ضمان تقديم الأفضل، والاستخدام الأمثل للموارد والعمل على التدريب المستمر للعاملين بالتعليم، والعمل على تقييم الأداء لضمان أفضل استثمار في العنصر البشري.

ثانيًا: مفاهيم تربوية مستخدمه في البحث Educational Concepts

توجد في الدراسات التربوية والتعليمية العديد من المفاهيم والمصطلحات التي عادة ما تستخدم بمعنى واحد، رغم الاختلاف والتمايز الذي يوجد بسبب التداخل والترابط والتكامل بينها منها ما يأتي:

1- Evans, R. James, the Management \& control of Quality, west Publishing Company U.S.A, 1998. 


\section{1.}

التربية في العربية تعني: إصلاح الشيء وتقويمه، وربّ الأب ولده اعتنى به وأحسن القيام عليه، وفي معناها العام تعني: التربية تحقيق النمو السليم المتكامل لكل من الفرد والمجتمع، وإيباد فرص التكيف بينهما.

ويتحدد معناها السلوكي بالتغير في سلوك الفرد، وأي تغير دائم يطلق عليه التعلم

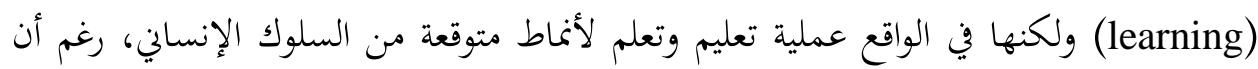

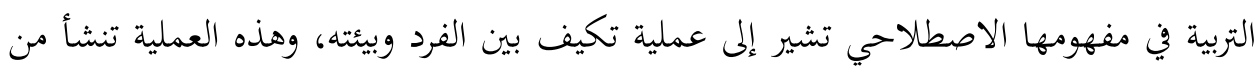
اشتراك الفرد بطريقة مباشرة أو غير مباشرة في مواقف الحياة، إلى أن تتشكل الشخصية. 2. التعلم والتعلم الذاتي Learning and Self learning: التعلم تغير عام يطرأ على سلوك الفرد في إطار عوامل ومتغيرات متفاعلة متداخلة متكاملة بين الفرد وبيئته. وقد ينظر إليها على أها (( عملية تعديل للسلوك وللخبرة كنتيجة للممارسة والتجربة، وتزويد الفرد بالمعارف والمهارات ))(1)، ويقاس مدى تقدم الفرد في التعلم بسرعة الأداء دون أخطاء (Acceleration) ومن مصادر التعلم الموارد البشرية وغير البشرية، التي يتفاعل معها الفرد داخل المدرسة أو خارجها، كالأشخاص، والأماكن، والبيئات، والأساليب، والوسائل، والطرق التعليمية. في حين أن التعلم الذاتي يعتبر أحد أساليب التعليم بحيث يكون فيه التلميذ معلما ومتعلما في آن واحد، وفق قدراته، وبما يمقق الاستقلالية، والحرية، والتنوع.

\section{3.}

التعليم هو عملية منظمة ومقصودة وهادفة، وموجهة بهدف مساعدة الأفراد على

1- أحمد زكي بدوي، معجم مصطلحات العلوم الاجتماعية، بيروت، مكتبة لبنان، 1982م، ص243. 


\section{4. التدريس Teaching:}

هو نقل المعلومات من المعلم إلى المتعلم، بقصد إكسابه ضروبًا من المعرفة وكإحدى الوسائل في تربيته(1). فهو كل نشاط يقوم به المعلم لمساعدة المتعلمين على تحقيق أهداف محددة.

General Aim ثالثًا: المدف العام من البحث

تهدف الورقة البحثية إلى إيضاح وإبراز أهمية توافر مقومات وأساسيات التعليم والتربية والتي من شأها تسهيل الأداء والوظائف المعاصرة للمدرسة أو عرقلتها؛ ويف ضوء الهدف العام والسؤال الذي يطرح نفسه:

ما هي المقومات الأساسية التي تحتاجها نجاح العملية التربوية والتعليمية، والتي تعمل على تطوير وتحسين الأداء وزيادة الفاعلية ودعم النمو المهني للعنصر البشري بالمدرسة؟

Elements of the Educational Process رابعًا: مقومات العملية التعليمية

تؤدي المدرسة وظائف غير نظامية بجانب الوظائف النظامية، على مستوى الأفراد والجماعات والمجتمع بشكل عام، بما يساعد على تنمية جوانب مختلفة من شخصية التلاميذ، وتزويدهم بالخبرات الإنسانية بعد تبسيطها وترتيبها بما يسهل استيعابها وينمى لدى التلميذ

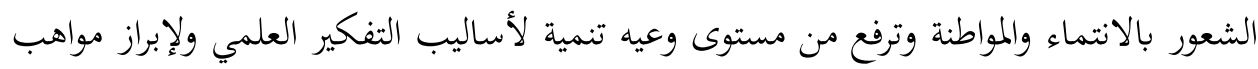

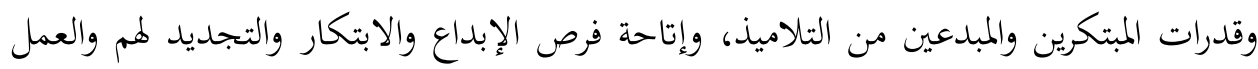
على تنميتها مع الكشف عن مشاكل التعليم عامة والتلاميذ خاصة، بالإضافة إلى وظائف المدرسة في الحفاظ على كيان المجتمع المعنوي من خلال نقل الميراث الثقافي، وتنقيته بما يعزز عملية الاستقرار والاستمرار والنهوض بالمتمع. وحتى تؤدي المدرسة وظائفها بكفاءة، عليها أن تعتمد على ركائز وأسس متداخلة

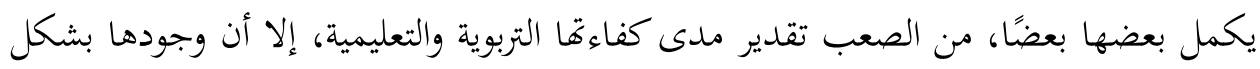
متكامل وفق اعتبارات علمية وتقنية فائقة، بما يتناسب مع احتياجات المتعلم والعاملين بالمدارس

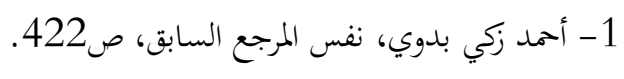


والمجتمع عامة، يساعد المدرسة على أدائها الوظيفي بفعالية. يرى فيها يُمَّم مصطفى زيدان

(1974) عوامل الكفاية الإنتاجية في التربية والتي يقسمها إلى ما يأتي (1): أولاً: مقومات بشرية (كالمدير، المعلم، المتعلم، الإداريين، الموجه....). ثانيًا: مقومات مادية (كالمبنى المدرسي، المعامل، المكتبة، الحديقة). ثالثًا: مقومات شبه مادية (كالكتاب، والوسائل، المنهج المدرسي).

\section{أولاً: المقومات البشرية للمدرسة :Human School:}

تتطلب الجودة في التعليم التركيز على العنصر البشري القادر على القيادة الناجحة من أجل تكوين ثقافة تنظيمية ترسخ الجودة العالية التي تغرس داخل المدرسة كسلوك ونمط تفكير

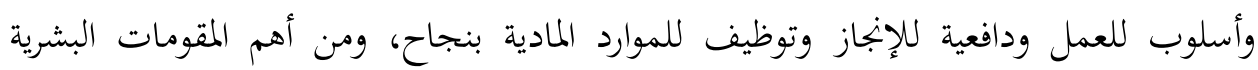
بالمدرسة مدير المدرسة والإداريون والمعلم والموجه والمتخصصون الاجتماعيون والنفسيون، والصحي، والمتعلم أساس الموقف التعليمي، وفيما يلي شرح وتوضيح (2):

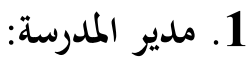

وهو الشخص المسؤول بصورة رسمية على تحقيق وظائف الإدارة المدرسية، بمساعدة معاونيه من الإداريين والمدرسين والموجهين. وتتأكد أهمية أدوار مدير المدرسة من المسؤوليات والمهام والمجالات التي يعمل وفقًا لها، سواء على مستوى التلاميذ أو العاملين أو المناهج والمباني والتجهيزات، وكافة المتطلبات والشؤون المالية وغيرها، سواء أكان على المستوى الفردي أو الجماعي أو على مستوى الإدارة بصفة عامة. وكفاءة مدير المدرسة في أداء وظائفه تتطلب مهارات متكاملة ضرورية للعمل الإداري،

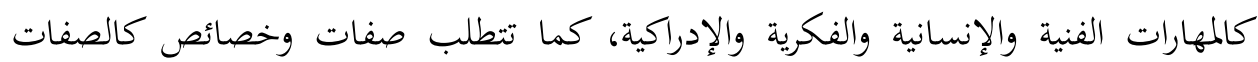
الجسمية والاجتماعية والنفسية والعقلية والفكرية والخلقية، وتعد الصفات الخلقية والذكاء أهم

1- مُحمّم مصطفى زيدان، عوامل الكفاية الإنتاجية في التربية، بنغازي- ليبيا، دار مكتبة الأندلس، 1974م.

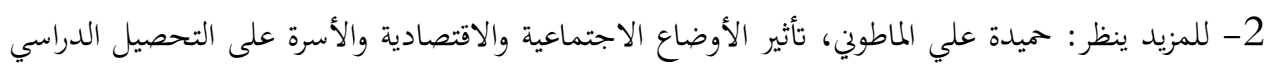

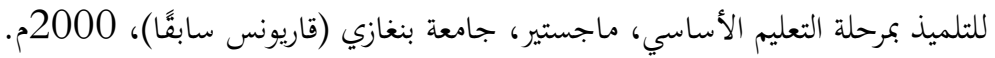


تلك الصفات التي يجب أن توجد في شخصية مدير المدرسة، بالإضافة إلى القدرة على توقع

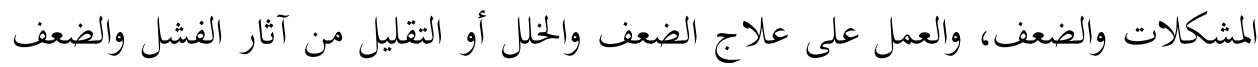
أو تفادي حدوثهما، بالإضافة إلى القدرة على ترسيخ علاقات اجتماعية، تسهم في بذل الجها والتعاون والتفاني في أداء الأعمال حسب أُطر علاقات إنسانية مطمئنة ودافئة ونمط قيادة ترئة ديمقراطي.

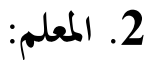

يعد المعلم المقوم الهام في العملية التربوية والتعليمية، باعتباره أساس الموقف التعليمي وأحد مكوناته الهامة. فالمقومات البشرية الأخرى أو المادية وشبه المادية تعد متطلبات تساعد المعلم على القيام بالمسؤوليات، والأدوار المتزايدة سواء على مستوى التلاميذ أو العمل أو المهنة أو المجتمع عامة. وينبغي عليه العمل مع كافة العاملين بالمدرسة، لمواجهة الظواهر الانحرافية وأي مشكلات مختلفة تواجه التلاميذ.

كما أن هذه المقومات لا تودي فعاليتها وكفاءقا إلا من خلال كفاءة المعلم، التي تشير إلى معارفه ومعتقداته وابتاهاته، وما يستطيع أن يفعله في موقف ما، ويستدل عليها من قدرته على إنجاز أهداف التربية والتعليم ومن خلال خصائص شخصيته وسلوكه. ولا يقل دور المعلم أهمية ومكانة عن مكانة ودور الوالدين في الأسرة؛ لأنه يقوم بوظائف تربوية ويشغل مكانة أساسية في البناء التعليمي المدرسي، ومن أهم صفات المربي الأساسية هي (1):

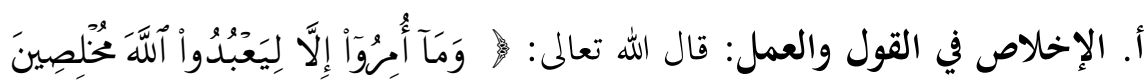

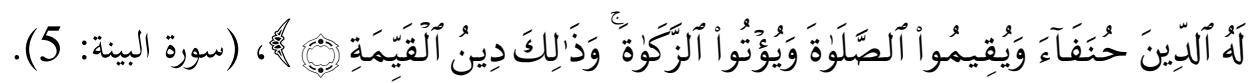
1- عبدالله ناصح علوان، تربية الأولاد في الإسلام، الجزء الثاني، دمشق-سوريا: دار الفكر، 2006م، ص583-578. 
ب. التقوى: يمكن القول أن تقوى الله وهو اتقاء عذاب الله بالمراقبة الدائمة لله

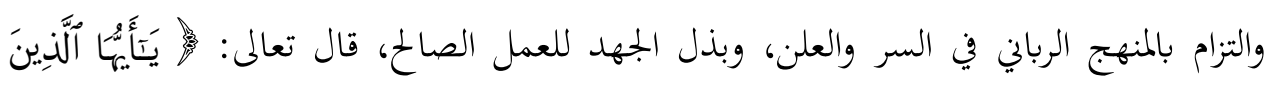

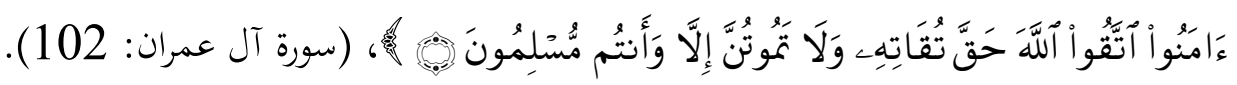
ج. العلم: التزود بالعلوم النافعة كأصول التربية في الشريعة الإسلامية، من أجل تربية

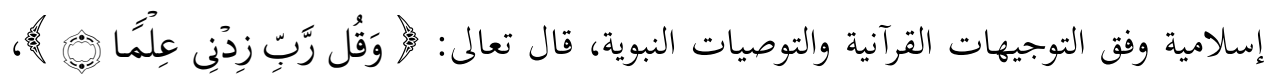

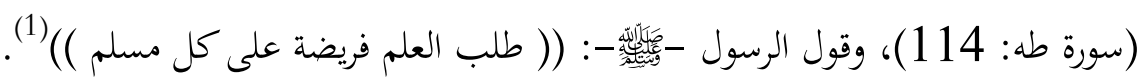
د. الحلم: رغب الإسلام في صفة الحلم والاتزان في الكثير من الآيات القرآنية، والأحاديث الشريفة؛ لأنه من الفضائل الخلقية والنفسية التي تجعل الإنسان في قمة الأدب وذروة

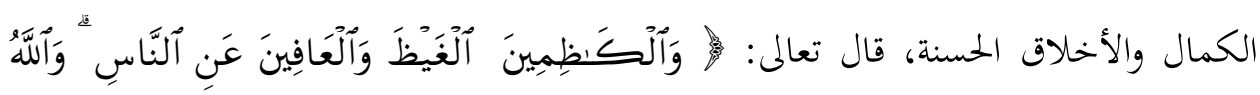

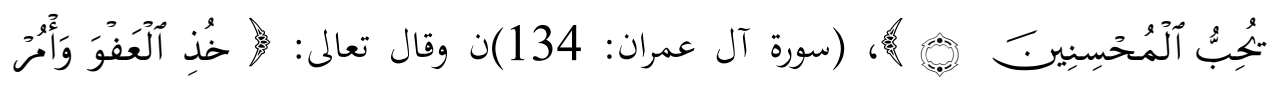

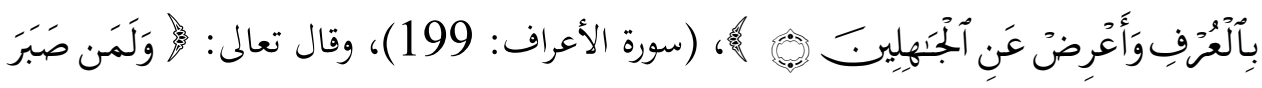

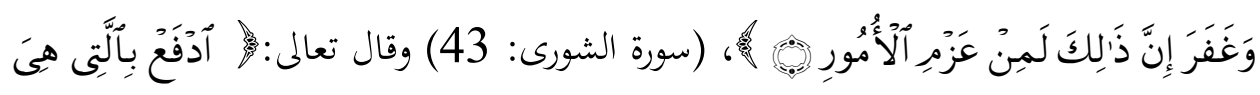

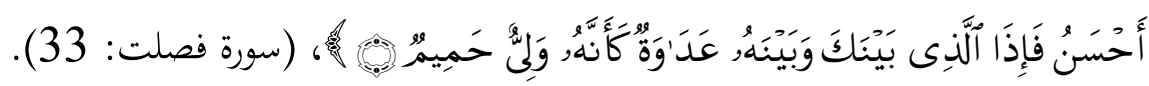
هـ. الشعور بالمسؤولية: يدفع إلى مضاعفة بذل الجهد، والمراقبة لما قدم من أعمال،

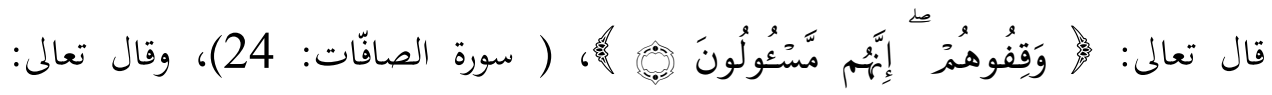

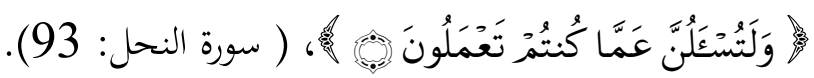

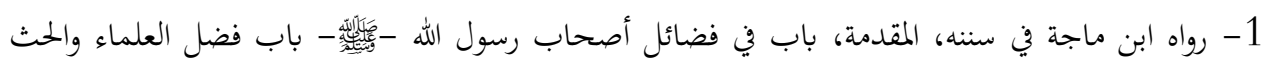

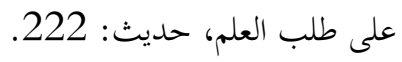




\section{3. الاختصاصي الاجتماعي والنفسي والصحي:}

إن الوظائف التربوية للمدرسة لا تقتصر على الجانب التحصيلي للتلميذ، وإنما تشمل تنمية شخصية التلميذ ككل متكامل، يستلزم وجود عناصر متخصصة يمكنها فهم متطلبات واحتياجات المتعلم والعملية التعليمية، بحيث تسهم في تنمية شخصية التلميذ، ولذذا وجدت الخدمة الاجتماعية كمهنة إنسانية متخصصة، كأداة للتغيير ولتحقيق الرفاهية للمجتمع المدرسي، بأسلوب علمي وفق مجالات وعمليات وطرق ومبادئ وأساليب وأهداف وفلسفة ومناهج الخدمة الاجتماعية.

والاختصاصي النفسي والصحي (Nursery) يمارس وظائف وأدوارا في المجال المدرسي غاية في الأهمية تكمل أدوار المعلمين وتذلل لهم الصعاب وفق إعدادهم العلمي والعملي في إطار طرق وفلسفة ومبادئ وأساليب وأهداف وأنشطة ومناهج وعمليات المهنة، التي تزود المدرسة بنوع خاص من الخدمات سواء على مستوى الفرد، أو على مستوى الجماعة، وتنظيم المجتمع كجزء من نظام متكامل يساعد المدرسة في أداء وظائفها من خلال الربط بين وضع سياسة اجتماعية واضحة المعالم في كل مدرسة.

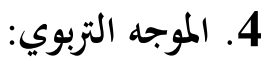

اتسع نطاق التوجيه التربوي والفني وتعددت مفاهيمه وأساليبه، فلم يعد بجرد عملية تفتيشية روتينية تمارس على المعلمين، وإنما أصبح عملية تربوية تحدف إلى تقديم خدمات تربوية واجتماعية للمعلم والمتعلم والموقف التعليمي حتى تسهم في بناء الموقف التربوي الأفضل، وتهيئة كل ما من شأنه أن يساهم في نمو المتعلم والمعلم. ولهذا تعددت تعريفات التوجيه أو الإشراف التربوي والفني، فقد عرف بأنه: خدمة فنية

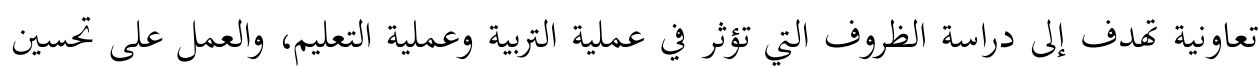
هذه الظروف بالطريقة التي تؤثر في عملية التربية وعملية التعليم، والعمل على تحسين هذه 
الظروف بالطريقة التي تكفل لكل تلميذ أن ينمو نموًا مطردًا وفق ما تدف إليه التربية المنشودة (1).

يتبين من هذا التعريف أن التوجيه أو الإشراف الفني عملية تؤدي عددًا من الوظائف

$$
\text { - قيادة تربوية تستهدف توجيه النشاط الجماعي. }
$$

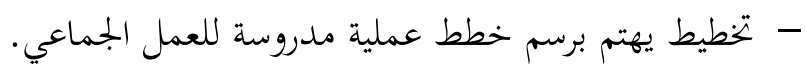

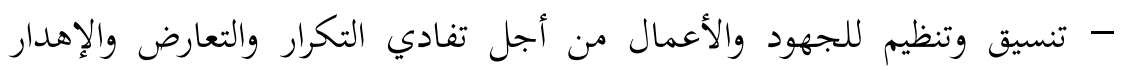

لكوقت والجهد.

$$
\text { - ت ت تدريب للمعلمين وتنمية الخبرات والمهارات الجديدة. }
$$

\section{:Learner 5 5}

المتعلم هو المقوم المهم والأساسي الذي من أجله أقيمت المدرسة، كما أن مقومات

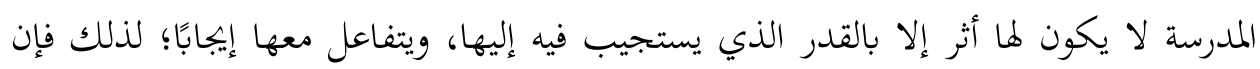

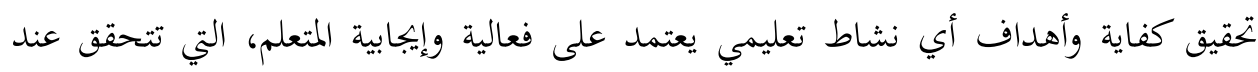

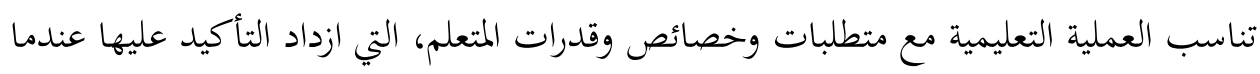
تأكدت فعالية التربية الحديثة، التي تتخذ من متطلبات وطبيعة خصائص التلميذ أساسًا هامًا في

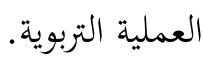

ومن الجدير بالذكر أن حياة الإنسان وحدة متكاملة في مختلف المراحل العمرية، ومن

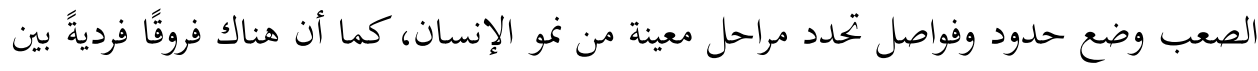
الأفراد إلا أن الدارسين والمتخصصين يلجؤون إلى إبراز النواحي الشائعة في كل المراحل العمرية.

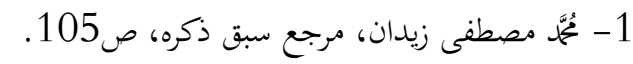

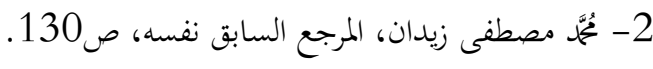




\section{ثانيًا: المقومات المادية للمدرسة ات}

تتطلب العملية التربوية والتعليمية توافر مقومات مناسبة هيكلية محددة، وليست بجرد مبانٍ وأماكن تخصص لأداء أكثر من وظيفة، فالتخطيط وحسن التصميم والجودة في المباني المدرسية يسهل أداء المهام والوظائف وفيما يلي شرح وتفصيل:

\section{1. المبنى المدرسي School Building:}

يعد المبنى المدرسي أحد المقومات المادية المهمة بما يؤدي من وظائف وأدوار متعددة مباشرة، أو غير مباشرة عندما يستوفي في بنائه وتصميمه الشروط والمتطلبات الصحية والتربوية

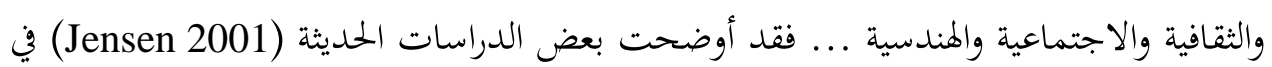
مجال علاقة التعليم بالدماغ: أن البيئات الغنية تنمي فعلاً أدمغة أفضل على اعتبار أن آلة الفكر (الدماغ) هي التي تشكل مخرجات التربية والتعليم؛ كما أن زيادة أعداد الطلبة في الفصول لكل مرحلة دراسية، وقلة الاهتمام بتصميم المبنى المدرسي، وعدم مراعاة التهوية والإضاءة الصحية

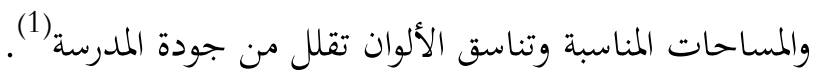
ولكن ينبغي الأخذ في الاعتبار أن جودة المباني والتصميمات النموذجية الحديثة ليست بالأكثر تكلفة، وأن الموارد المادية للمدرسة في حالة عدم توظيفها بكفاءة تعد مجرد مواد ولا معنى لها في معيار الجودة.

وفقًا لهذا المنطلق تعد المدرسة وسطا بيئيا وبيئة تربوية ثانية بعد الأسرة، يقضي فيها المتعلم والعاملون بها جزءًا كبيرًا من وقتهم، وبهذا تسعى الاتحاهات الحديثة في التربية إلى تحسين مقومات المدرسة حتى تحقق أهدافها ووظائفها الترفيهية الهامة في إشباع الحاجات، وتوفير متطلبات التعلم والنمو، والاهتمام بجميع جوانب شخصية المتعلم وفق متطلبات النمو الشامل

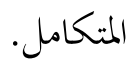

1- جينس إيريك، كيف نوظف أبحاث الدماغ في التعليم، ترجمة دار الكتاب التربوي للنشر والتوزيع، الدمام، 2001 
كما يمكن القول أن الدلالات التربوية للمكان ليست بما تحمل من مواصفات المباني الحديثة المتطورة اللازمة للتعلم الفعال، بما يوفر من مقومات فاعلة كحرية الحركة واللعب والترفيه والاستقلالية، فوجود الحديقة المدرسية لا يعني أها أدت وظائفها الترفيهية، كما أن وجود أجهزة الحواسيب (Computers) في المدارس ليس مؤشرًا على جودة المدرسة، على سبيل المثال المدارس الليبية قد لا تستخدم أجهزة الحاسوب إلا في بعض الأوقات كطباعة أسئلة الامتحانات، في حين ظلت بعيدة عن متناول المعلم والمتعلم. فدلالات المكان و تأثيراته غاية في الأهمية، وكما اتضح من نمنيم نتائج دراسة ميدانية -حميدة الماطوين 1999م- بمدينة بنغازي أن تأثير سكن الأسرة في التحصيل الدراسي للتلميذ

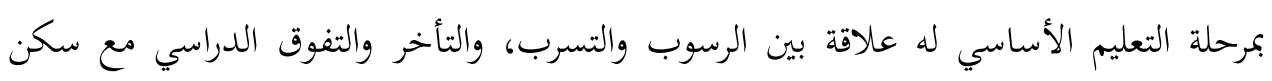

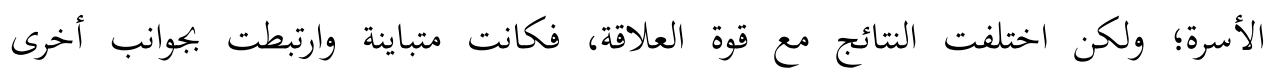
كتخصيص مساحات من المسكن للتلميذ، ولو بصورة مؤقتة مع حرية الاستعمال المباشر للأشياء المتاحة بالمسكن (1) وبهذا يمكن القول أن المباني المدرسية تؤدي أدوارًا وظيفيةً متعددة، كالتحصيل الدراسي والاتحاه نحو المدرسة ... واستقرار العاملين بالمدرسة ... في حالة استيفاء المبنى لمواصفات ودلالات ومعايير الجودة، التي تتضمن الموقع العام المناسب للمدرسة، والمساحة

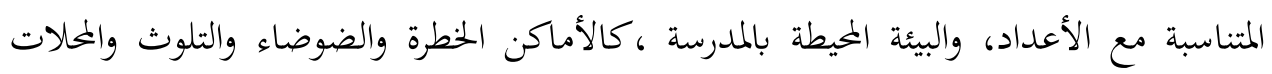
العامة والصناعية والتجارية ... مباني يتوافر فيها الأمن والسلامة والسهولة في الحركة للمواصلات

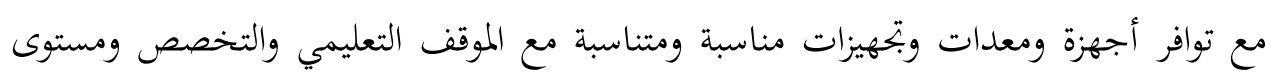
التلميذ الزمني والعقلي، وفي هذا الخصوص سبق وأن درست الباحثة بمدرسة العلوم الاجتماعية

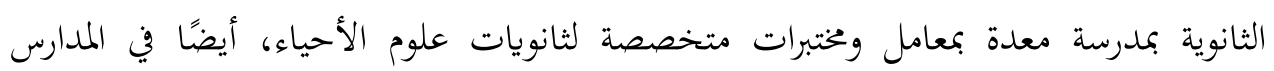
الابتدائية بالفترة المسائية ننتظر مع التلاميذ لحين خروج طلبة الفترة الصباحية من الفصل الذي مئري

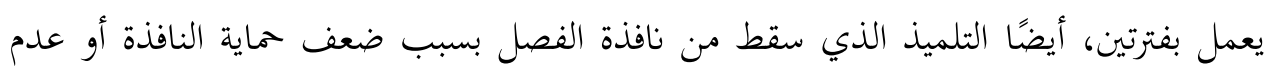

1- حميدة علي الماطوني، مرجع سابق، ص168-169. 
وجودها، حقيقة أمثلة وصور عالقة بأذهاننا نأمل أن نبني لأبنائنا مدارس تليق بحجم المهام

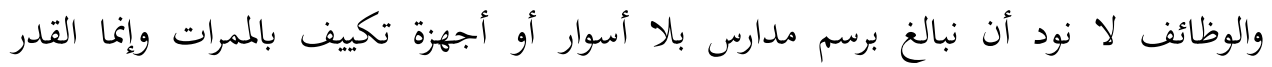
المناسب الذي يليق بمن يجلسون على المقاعد المدرسية، من نظافة المكان والأدوات الإضاءة الصحية والتدفئة والتهوية المناسبة والرطوبة النسبية والسلامة والأمن والوقاية من المخاطر .

School Laboratory 2

تؤدي المعامل المدرسية المجهزة بعناية وفق المتطلبات التعليمية والتجهيزات والمعدات المناسبة للموقف التعليمي دورًا أساسيًا في إعداد النشء، وفي توفير دراسة علمية منظمة، وخبرة عملية معاشة في حجرات متخصصة بما يساعد على التدريب على اتباع الأسلوب العلمي في البحث والاستقصاء والمشاهدة الفعلية.

وعليه من الأهمية والفعالية أن تعد المعامل المدرسية للتدريب العملي وفق أجهزة ومعدات وأدوات ووسائل تتناسب مع الموقف التعليمي، والتي تضفي على المدرسة الفائدة العملية والاستثارة والاستماع بما يقدم وفق تقنية متقدمة.

\section{Play Ground الملاعب المدرسية}

اللعب play والترويح Recreation نشاط يمارسه الإنسان ويستمتع به، والترويح للمتعلم نوع من التربية الاجتماعية، حيث يبيح فرص التعامل مع الآخرين في جو من المرح والحرية وله أدوار ووظائف جسيمة وعقلية واجتماعية ونفسية وغيرها، بما يتيح من فرص لصقل

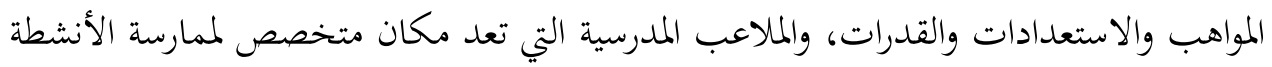

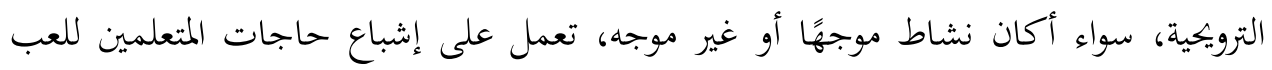
والحرية والحركة والترفيه، والسؤال الذي يطرح نفسه هو: هل توجد ملاعب مدرسية؟ وما نوعيتها؟

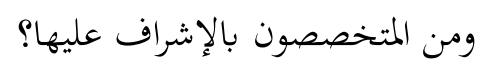

\section{School Garden الحديقة المدرسية}

تأتي أهمية وجود حديقة مدرسية محفزة للتفكير وتبعث الشعور بالارتياح، فيجعل الشمدئ المكان يبعث على السرور والراحة خاصة إذا كانت محتويات المكان يعكس الطبيعة والجمال. 
وحديقة المدرسة يبقى التركيز على دورها ليس للترفيه والترويح فحسب، وإنما دورها أساسي في التربية البيئية والتربية الصحية من أجل الحفاظ على البيئة، والاهتمام بصحة التلاميذ،

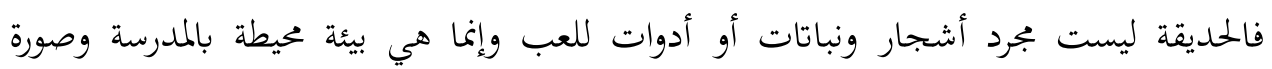
مصغرة لما في داخل المجتمع.

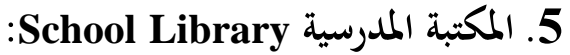

تُعد المكتبة المدرسية جزءًا أساسيًّا وهامَّا في العملية التعليمية والتربوية، ودعامة للمنهج المدرسي على اختلاف مراحله ومستوياته وتخصصاته، وإن كانت الملاحظة العامة أن الاستناد

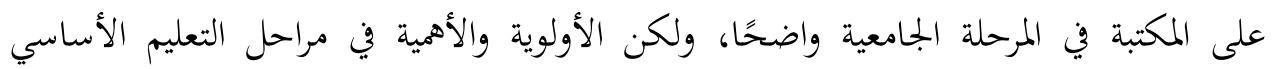
والثانوي لا تقل أهمية في دعم المنهج المدرسي والعملية التربوية، الأمر الذي يتطلب إعادة النظر في واقع مكتباتنا المدرسية -إن وجدت- بناؤها واحتياجاتما وسبل تطويرها؛ بل وفي المكتبات العامة باعتبارها مركز إشعاع تربوي، أو أحد وسائل نقل الثقافة والمعرفة بين الأمم والشعوب. وفي المدرسة تسهم المكتبة المدرسية في التغلب على كثير من المشكلات التعليمية وفي ترني توسيع قدرات ومهارات المتعلم وإتاحة الفرص الناجحة والمعد بعناية للإفادة من خبرات وبحارب الآخرين، وتشجيعهم على القراءة الحرة وغرس الكثير من الاتجاهات والقيم المرغوبة، والعادات الإيجابية في الاطلاع والبحث والتعاون والحرية والانتظام والعمل الجماعي وممارسة هوايات القراءة والتعلم الذاتي النافع والمفيد، كما تساعد المكتبة المدرسية المعلمين في إثراء الدروس، وهذا متوقف على المقومات الفاعلة المتوافرة في المكتبة المدرسية، كالتجهيزات (Enrichment) المعدة بعناية والوسائط التكنولوجية المتاحة، والموقع المتميز للمكتبة بمواصفات حديثة، وإمكانيات متطورة إلى جانب كادر وظيفي مؤهل بفعالية يجعل منه أحد روافد العملية التعليمية والتربوية تؤدي دورها وأنشطتها المتنوعة كالمحاضرات والمسابقات والمعارض والنوادي الصيفية(1).

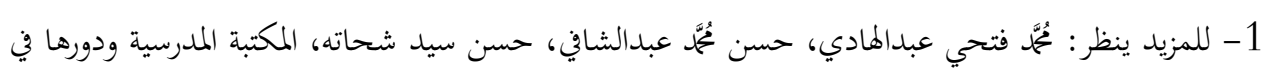

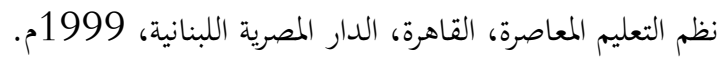


لا شك أن العمل على إيجاد مجموعة منظمة من مصادر المعرفة والمكتبة الإلكترونية

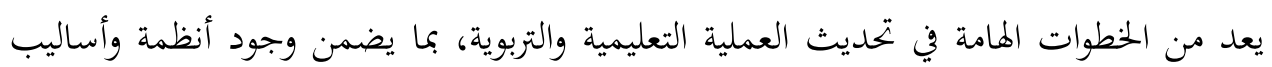
معلوماتية حديثة تضبط وتعالج المعلومات بشكل سريع، وتعمل على تحسين وارتقاء العملية التعليمية، وتقدم خدمات تعليمية بأساليب متقدمة وخطوات تصميمية تضمن مهارات البحث داخل المكتبة. واستخدام الحاسوب بشكل دوري يثقف المعلم بمزايا التعليم الذاتي، ويعزز المناهج المدرسية ومواكبة للعصر وتوفير للجهد والوقت على المعلم في كثير من المواقف التعليمية، وين متابعة وتقويم أداء التلميذ خاصة في المراحل الجامعية. إن فعالية المكتبة تتوقف على كفاءة العاملين بها، وجودةما وتميز ودقة خدماهما، فالخدمات المرجعية والإعارة بأنواعها من مصادر دعم لفعالية وظائف المكتبة.

\section{6. حجرة الطعام (المقصف) Cafeteria}

الوجبات الغذائية عنصر مهم لتحقيق حاجات فسيولوجية حيوية، ينبغي انتقاؤها بما يوفر من عناصر مغذية، ومقصف المدرسة يؤدي وظيفة حيوية في إشباع حاجات التلميذ، للأكل والشرب أساس النمو الجسمي.

إن بناء جسم سليم وغرس ثقافة صحية، ينبغي أن تكون من الأولويات التي ينبغي على المدرسة التركيز عليها، مساندة لدور الأسرة، ونقل الثقافة الصحية للأسرة، كجسر تواصل

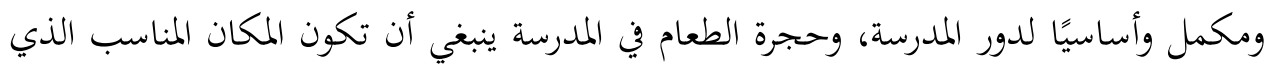
يشرف عليه المشرف الصحي في تقوية التلاميذ والأسرة على الاختيار والافتقاء المناسب للصحة العامة للإنسان.

\section{ثالثًا: المقومات شبه المادية للمدرسة:}

تتكامل المقومات شبه المادية مع المقومات التربوية الأخرى في دعم رسالة المدرسة وتحقيق أهدافها، وتتمثل هذه المكونات في توافر العديد من المتطلبات والمحتويات والتقنيات وفق المستجدات التربوية المعاصرة أهمها ما يأتي: 


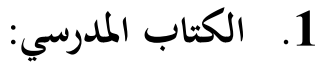

رغم التنوع والتطور في وسائل الحصول على المعلومات، ووجود البدائل الذكية والسهلة

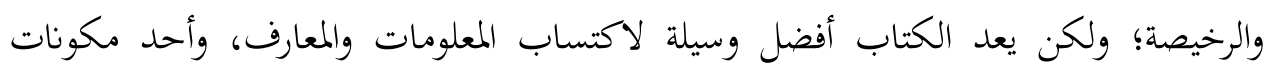
المنهج المدرسي.

وأهمية وجود الكتاب المدرسي بالمدرسة، وفي حجرات التدريس مصدر دعم للموقف التعليمي، ومساندة للمعلم في تقديم إطار عام للمقرر الدراسي، ووسيلة متاحة ومناسبة لعرض

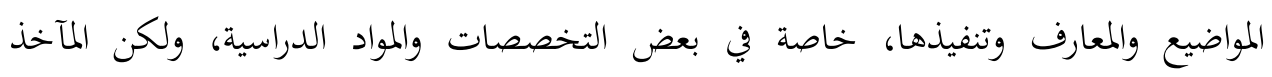

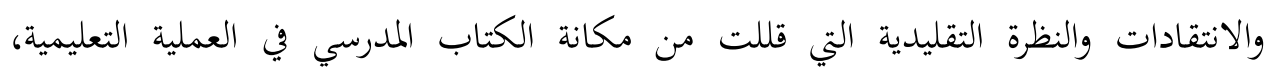
والاعتماد عليه كمصدر وحيد وأساسي، والتركيز عليه من أجل الحفظ والاستيعاب وتوظيف

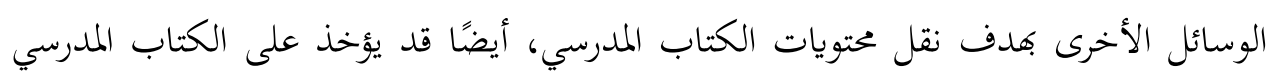
ضعف محتواه وقلة فعاليته مجرد حشو وسرد مفصل لمواضيع ليس لها دلالات تربوية.

\section{2 التخطيط التربوي:}

أصبحت المجتمعات المتقدمة تعول على التخطيط في جميع أمورها الحياتية خاصة التعليم، وعند الحديث عن التخطيط كأحد وظائف الإدارة، يتبادر إلى الذهن التفكير في يوم غلٍٍ، فالتخطيط يستخدم للوصول للأهداف المستقبلية التي يراد بها تحقيق وتنفيذ المهام حسب الإمكانيات. إذن فهو نشاط وجهد إنساني منظم، شامل، مستمر من أجل تحقيق الأهداف المحددة.

والتخطيط التربوي هو رسم السياسة التعليمية بكامل صورتا، مع مراعاة للأوضاع والظروف المحيطة كالاجتماعية والاقتصادية والسكانية، وذلك من أجل تنمية رأس المال البشري - التلميذ- فهو عملية تسير نحو التقدم متصلة ومستمرة (Process) متصلة مستمرة تتطلب أساليب البحث العلمي والاجتماعي، ومبادئ وطرق التربية وعلوم الإدارة والاقتصاد، وللتخطيط أنواع ومستويات وخطوات وخصائص وفوائد ووظائف غاية في الأهمية. 


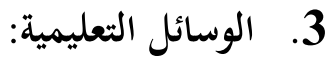

تعد الوسائل التعليمية مصدر دعم وإثراء للعملية التعليمية، وتسهم في تحقيق أهدافها المحددة والمرجوة، ولكن وفق شروط واعتبارات وأسس، ينبغي على المعلم وضعها في الاعتبار قبل

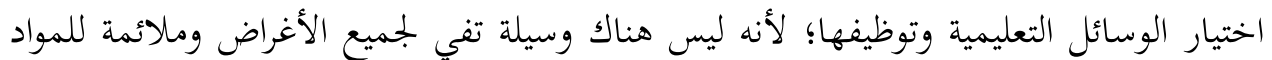

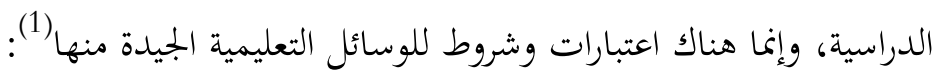

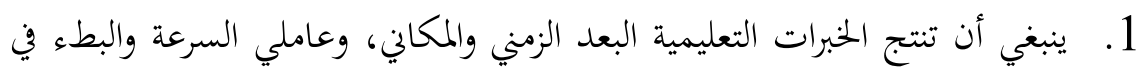

الخبرات المتاحة، وأن تكون نابعة من المقرر الدراسي وتسهم في تحقيق المدف المحدد منها.

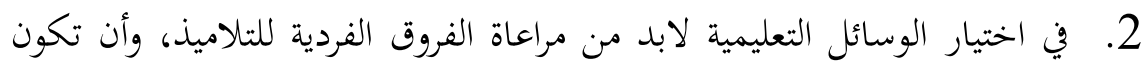
مناسبة للعمر الزمني والعقلي للتلميذ. 3. أن تنتج الوسائل فرص النمو والتعليم الذاتي والتعليم المستمر . 4. أن تعالج مشكلات المعلمين كالنقص في الإعداد والتخصص أو عدم الكفاءة. 5. أن تضمن الوسائل مشاركة فعالة من التلاميذ لأن إتاحة فرص المشاركة من وسائل نمو الدافعية للعمل وأثره. 6. أن بحمع وتوفق بين الدقة العلمية والجمال الفني. 7. أن تناسب فيه الوسائل التعليمية مع متطلبات البيئة وثقافتها وقيمها. 8. أن تكون الرموز المستخدمة ذات معنى ومدلول مشترك وواضح ومحددة بدقة. 9. التبسيط بقدر الإمكان بما يسهم في وضوح الأفكار ولا يلغي الحقائق.

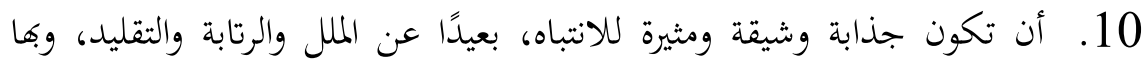
شيء من الحركة والمرونة والابتكار وإشباع حاجة التلميذ للتعلم. 11. أن يتناسب مع الموقف التعليمي ومع عدد الدارسين، وتكون في واجدة المتناول بعيدًا عن التكلف بقدر الإمكان وفق اقتصادية التعليم.

1- - حسنية مُجمَّ حسن المليجي، موديول الوسائل التعليمية وتكنولوجيا التعليم، مشروع تطوير برنامج التربية

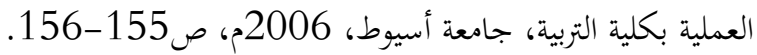


12. مراعاة الاتفاق في التصميم والشكل والتركيز على الأهداف.

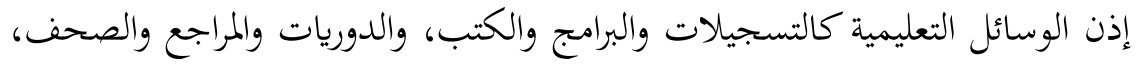

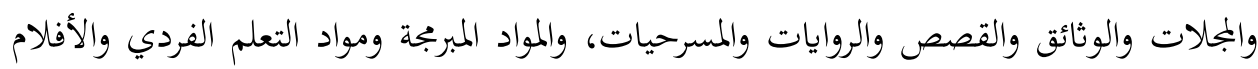

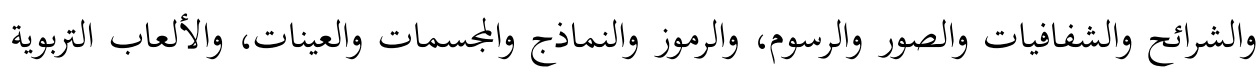

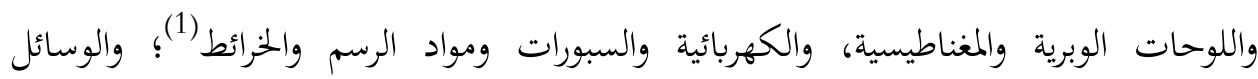

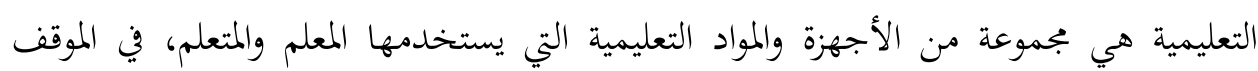

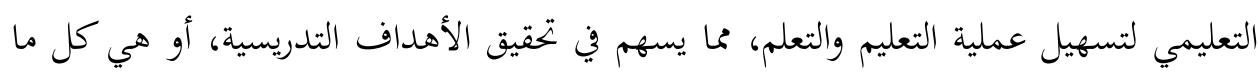

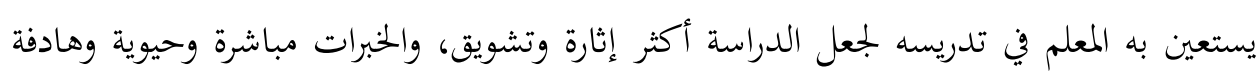

$$
\text { وفق عناصرها الهامة (المواصفات - المواد - الأجهزة - الأشخاص). }
$$

\section{4.}

تغيرت النظرة للمنهج المدرسي من التركيز على المواد الدراسية ومحتوى المقرر الدراسي،

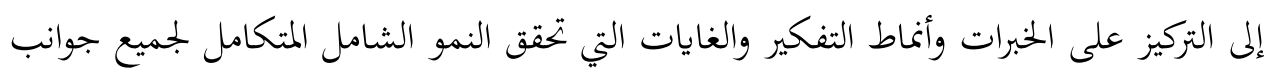

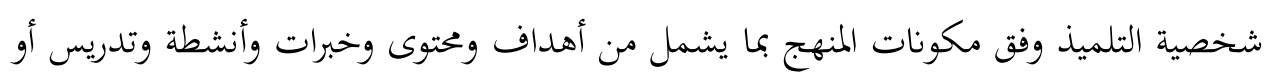

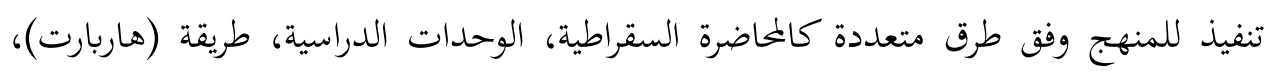

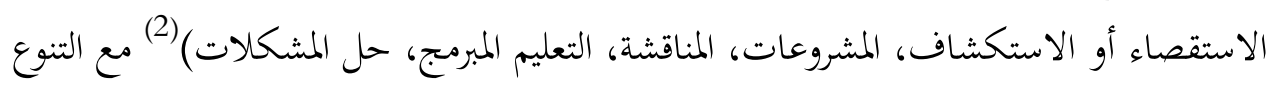

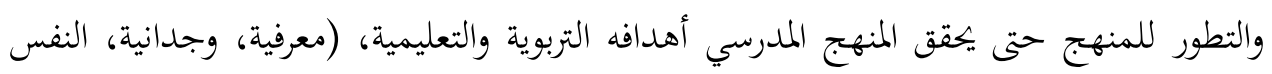
حركية)، ومما ينبغي التركيز عليه هو الاهتمام بقضايا الطلبة المتميزين من الموهوبين في المنهج المدرسي، (Issues Related to Gifted \& Talented School Curriculum)، والتركيز

1- للمزيد ينظر: مُحمّه محمود الحيلة، تصميم التعليم نظرية وممارسة، ط3، عمان-الأردن: دار المسيرة للنشر

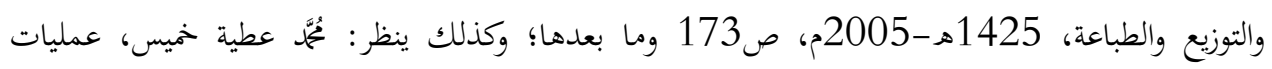

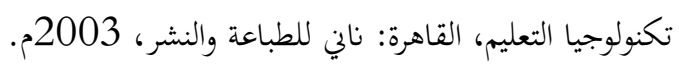

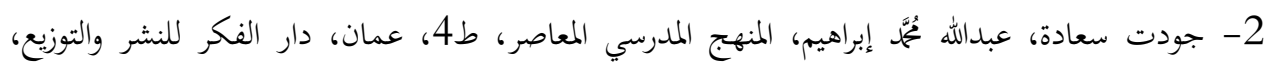
2004 . 
على ضرورة توفر مناهج تربوية فعلية متكاملة متوازنة ومرنة ومتطورة، تلبي احتياجات المتعلمين ومتطلبات خطط التنمية، واحتياجات ومتطلبات المجتمع وسوق العمل المستقبلية، كما يستوعب تروبت

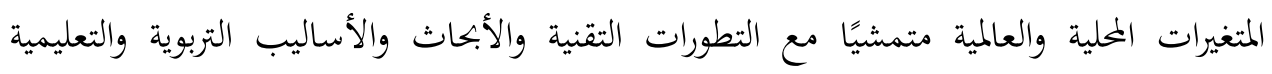
المعاصرة، وفق مبادئ وقيم التربية الإسلامية، وتتم عملية تطوير المنهج المدرسي في ضوء تحدي فلسفة التطوير وصياغة الأهداف وتطويرها، مع رسم خريطة للمنهج والعمل على تقدير وتقييم

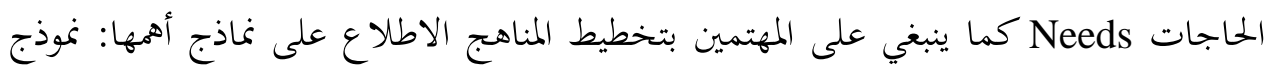

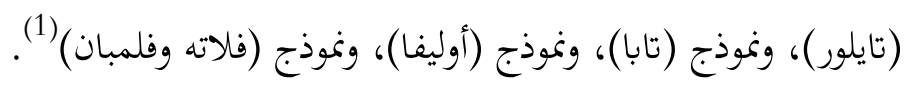
خامسًا: ملخص البحث والمقترحات والتوصيات

وقبل الختام: أحمد الله تعالى الذي منَّ عليَّ بكتابة هذا الجههد والسعي إلى عرضه، وأدعوه -عز وجل- أن يفيد به وطننا الغالي، الذي يحتاج منّا إلى بذل المزيد من الجهد والعطاء من أجل بناء ليبيا الحبيبة، والذي نأمل أن يكون نافعًا لزملائنا وإخوتنا المعلمين والموجهين والمهتمين بالعملية التربوية، كما ننوه إلى أن هذا جهد إنساين لا يخلو من التقصير والسهو والنسيان، فالكمال لله وحده، نأمل من القراء والمهتمين والعاملين أن يفيدوننا بملاحظاتم وتوجيهاتم للارتقاء بمثل هذا الجها الذي حرصنا على إبراز أهم مقومات ومهكونات العملية التعليمية وإن قسمت إلى ثلاثة محاور أساسية كالمقومات البشرية والمادية وشبه المادية إلا أهما متكاملة مترابطة، فالغرض من أجل التبسيط والدراسة، كما أن المدرسة في مهامها ووظائفها ليست معزولة عن البيئة المحيطة كالمجتمع المحلي، كما أن كفاءة المدرسة نتطلب تكامل وتعاون وتناسق الأدوار خاصة الأسرة من أجل إعداد الإنسان المتكامل وفق تربية دينية عقلية جسمية إعلية

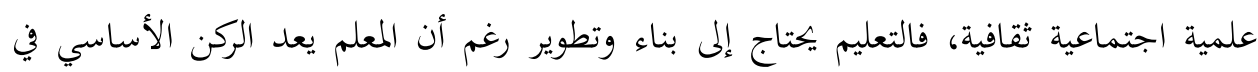

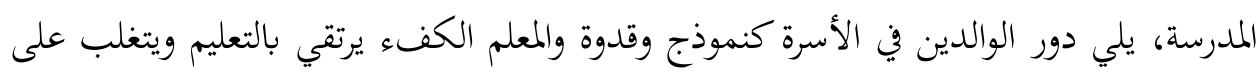
الصعوبات والعقبات، في حين أن المعلم غير الكفء يقلل من المقومات الممنوحة له، والمقومات

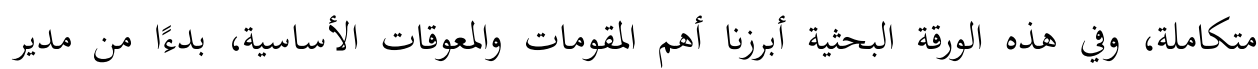

1- جودت سعادة، عبدالله يُمَّمَ إبراهيم، مرجع سبق ذكره، ص494. 
المدرسة، فالمعلم والموجه والمتخصص والعاملين بالمدرسة، مع توافر مقومات مادية كالمبنى المدرسي

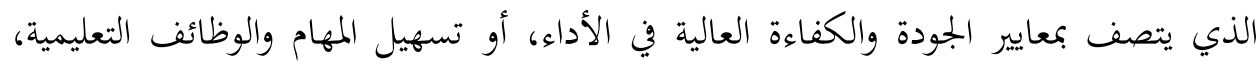
بالإضافة إلى توافر المعامل والملاعب، والحديقة المدرسية والمكتبة المدرسية، التي يعول عليها الكثير في دعم لرسالة المدرسة مع توافر مقومات الوسائل التعليمية المعاصرة والمتطورة، وفقًا للمنهج المدرسي الذي يتناسب مع متطلبات الحاضر والمستقبل، متبعًا لسياسة التخطيط التربوي الذي يعول عليه الكثير في الرقي بالمدرسة. مع هذا الملخص نبرز بعض التوصيات والمقترحات التي نأمل فيها الإثراء والإغناء

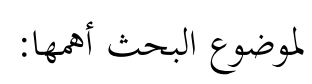

1. إن بذل الجها والعناية بمراحل التعليم الأساسي يعد عملاً إنمائيًا غاية في الأهمية، فالاهتمام بهذه المراحل العمرية يعد ركيزة أساسية لمراحل التعليم اللاحق كالإعدادية والثانوية والجامعية.

2. تحتاج المقومات والمكونات التعليمية بالمدارس الليبية إلى إعادة النظر، فيها

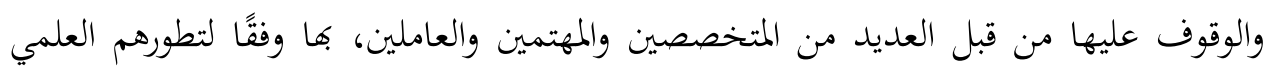
والعملي، فهي إن عرضت في نقاط بهذه الورقة يحتاج كل جانب فيها إلى أبحاث ودراسات مفصلة وواسعة النطاق.

3. الإسلام دين العلم والانفتاح على التجارب والخبرات الأخرى، لا يعني النظر إلى ولى ما عند الآخرين ونسيان واقعنا المعاث وثقافتنا وخصوصيتنا، فالكثير من الأمور والقضايا التربوية التعليمية التي يصعب احتوائها من منظور التجارب الغربية، أن ستفادة من بتحارب الدول التي نجحت وتقدمت تعد مصدر دعم وتعزيز وإثراء، وليست مصدرًا أساسيًا لاحتوائها.

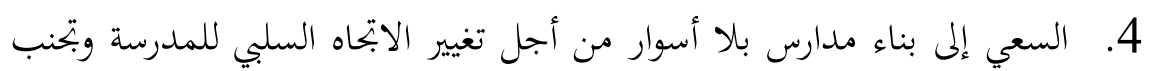
عزل المدرسة عن المجتمع المحيط وغرس ثقافة بنائه أساسها المدرسة بيئة مكملة للأسرة. 5. المدارس التى تقدم وجبات غذائية للتلاميذ، فكرة رائعة ولكنها في ظل ثقافة

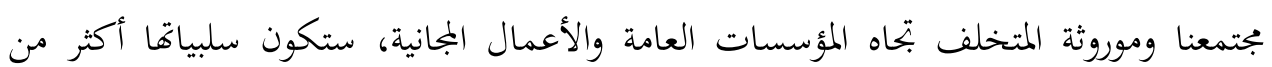


إيجابياها، وإنما نأمل إلى تفعيل دور المشرف الصحي في الإرشاد الأسري من أجل بناء ثقافة صحية في المدرسة والمجتمع.

6. أوضحت نتائج العديد من البحوث والدراسات التربوية أهمية مكانة المعلم في المدرسة والمجتمع، وأهمية الأدوار والوظائف المباشرة وغير المباشرة، التي يقوم بها المعلم، فالتركيز

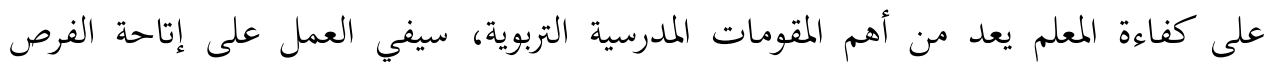

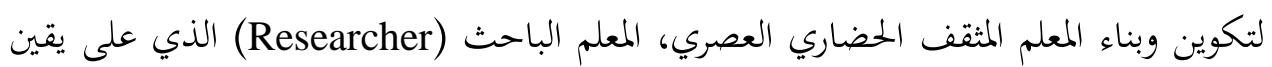

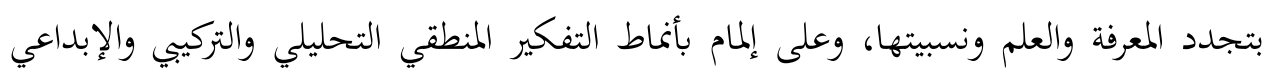

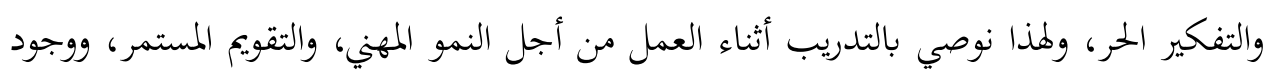
مقاييس في الاختيار، ومتابعة الصحة النفسية للمعلم. 7. العمل على إيجاد جهد تعاوني وتضافر الجهود من أجل توفير رعاية اجتماعية وصحية ونفسية بالمدارس الليبية، خاصة بعد ظروف الحرب التي مرت بها البلاد ولازالت تحصد ويلاتها.

8. الإدارة هي المرتكز الأساسي للعمل في المدرسة من خلال وظائفها، ستبني العديد من البرامج والخطط الوقتية والمستقبلية ينبغي التركيز على إعداد مدير المدرسة، و تأهيل ورفع كفاءته ومهاراته، باعتباره في قمة الهرم المدرسي كقائد إداري. 9. المتعلم أساس وجود المدرسة والتي من أجله أقيمت، ولابد من فهم متطلباته واحتياجاته وفقًا للمرحلة العمرية والعقلية المناسبه له. 10. ربط المدرسة بالأسرة والمجتمع عامةً، فهذا استمرار للعمل التربوي وضمان لتكامل الأدوار والوظائف، ينبغي على المدرسة مراعاقا وفق برابجها. 11 1. إثراء المواد الدراسية والعمل على تطويرها بمراجعتها وإضافة العديد من المواد التي يحتاجها سوق العمل، ومتطلبات المجتمع المعاصر كمادة الثقافة الأمنية والصحية والسلامة. 
12. إعادة النظر في الوعاء الزمني لمدارسنا، وهل هو يناسب تطلعاتنا، والعمل على

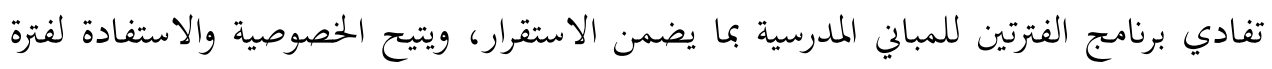
زمنية أطول. - مان.

13. وضع القوانين التي تضمن الحماية والأمن للعاملين وحقوقهم، وتوفير الحماية المناسبة لممارسة العمل بقطاع التعليم. 14. مراجعة إدارة التعليم باعتبارها العنصر الأساسي الذي يسير وينفذ الأعمال

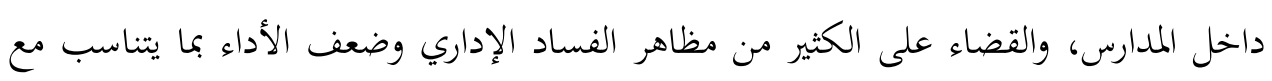

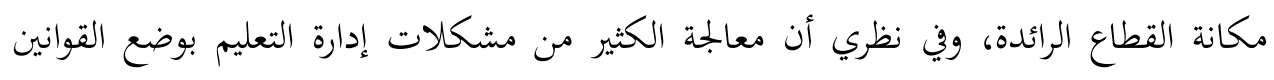

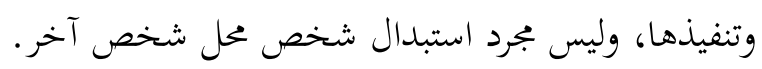

15. التركيز على الأنشطة والبرامج التعليمية الترفيهية والترويحية في المدارس، لأهميتها في أداء الوظائف وتحقيق الأهداف. 16. العمل على غرس ثقافة أهمية وجود مكتبة بالمنزل كأحد وسائل شغل وقت الأل الفراغ، والتشجيع على التعلم الذاتي والعمل على رفع ثقافة المجتمع بدئًا بالأسرة.

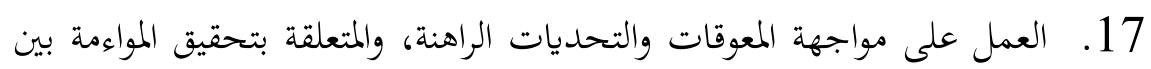

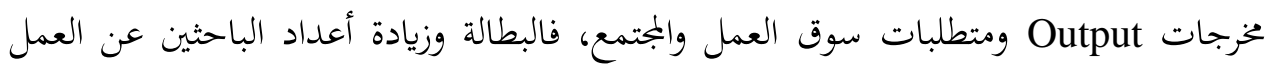
من الخريجين أصبحت سمة واضحة بالملاحظة في مجتمعنا اللبيي.

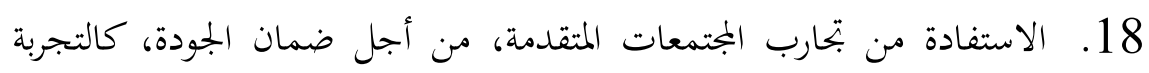

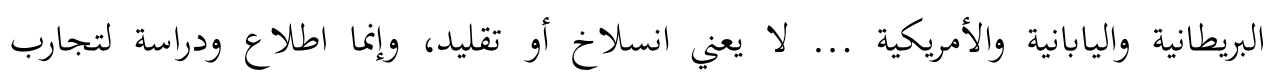

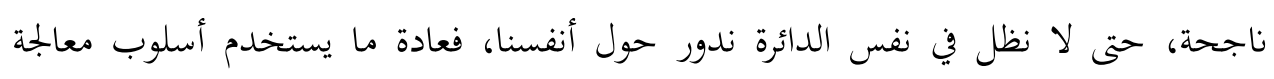

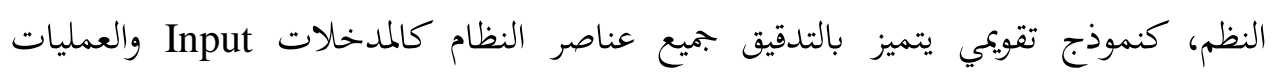
Output والمخرجات Process 


\section{المصادر والمراجع}

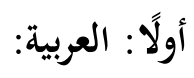

1- أحمد زكي بدوي، معجم مصطلحات العلوم الاجتماعية، بيروت، مكتبة لبنان، 1982م.

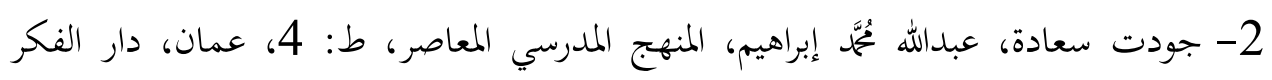
للنشر والتوزيع، 2004م. 3- جينس إيريك، كيف نوظف أبحاث الدماغ في التعليم، ترجمة دار الكتاب التربوي للنشر والتوزيع، الدمام، 2001م. 4- حميدة علي الماطوني، تأثير الأوضاع الاجتماعية والاقتصادية والأسرة على التحصيل الدراسي

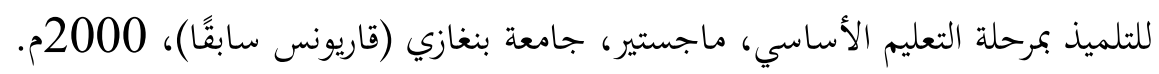
5- عبد اللطيف بن الصفي الجزار، مقدمة في تكنولوجيا التعليم النظرية والعملية، القاهرة، كلية

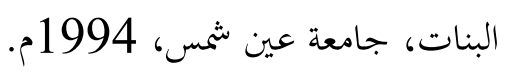

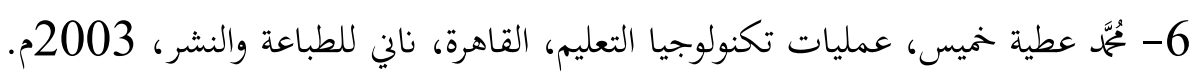
7- مُحمّمَ فتحي عبدالهادي، وآخرون، المكتبة المدرسية ودورها في نظم التعليم المعاصرة، القاهرة، الدار المصرية اللبنانية، 1999م. 8- كُمَّمَ محمود الحيلة، التصميم التعليمي نظرة وممارسة، عمان، دار الميسرة للنشر والتوزيع والطباعة، 1999م. 9- بُمّمج محمود الحيلة، تصميم التعليم نظرية وممارسة، ط: 3، عمان-الأردن، دار المسيرة للنشر والتوزيع والطباعة، 1425- 2005م. 
10- مُحَّم مصطفى زيدان، عوامل الكفاية الإنتاجية في التربية، بنغازي-ليبيا، دار مكتبة

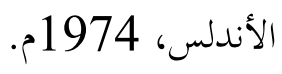

\section{ثانيًا: الأجنبية:}

1- Bullock. A. and Thomos. H., "school of the center", London and New York Routledge, 1996. 1- Hopkins, D., et. Al, "Improving the quality of Education for All", London, David Fulton Publishers, 1996.

2- Evans, R. James, the Management \& control of Quality, west Publishing Company U.S.A, 1998.

3- Roger slee, and Gaby weiner (ed.), "introduction: school effectiveness for whom?" in: "school effectiveness for whom", London, Falmer Press, 1998. 